\title{
The diurnal variation of intraocular pressure - the most important symptom for early detection and follow-up of the glaucomas
}

\author{
Jorg Draeger
}

Received: 27 May 2010 / Accepted: 12 June 2010 / Published online: 2 July 2010

(C) Springer-Verlag 2010

\begin{abstract}
Hans Goldmann in 1958 emphasized the importance of the diurnal curve of intraocular pressure for very early detection of glaucoma. He stressed from the investigations of Leydhecker (1959) that there is a 10 -year interval between early detection of chronic glaucoma and the first signs of neuronal defects or even later, functional problems. Roberto Sampaolesi (1974) finally has proven the important innovation from his great number of diurnal curves. Of course, a precise diurnal curve (Sampaolesi asked for eight measurements) is almost impossible by the ophthalmologist's office or even within the hospital. We need the cooperation of the patient (like we do this in blood pressure measurement or even diabetes control). This requires an easy-to-handle "self-tonometer", which allows measurement at any time of the day, even in different positions of the patient's body. Due to some difficult technical problems to be solved, it took until 1988 before the "automatic selftonometer" was available. This was first tried in three space missions (Spacelab D1, 1985; Spacelab D2, 1993; German-Russian MIR-Mission 1992) allowing for the first time to register the enormous increase of intraocular and intracranial pressure after entering into microgravity. Some years later, the first instrument for clinical application was available, allowing a large series of dense diurnal curves, confirming Goldmann's and Sampaolesi's hypothesis. The technical solution, application, and results with this new instrument are described.
\end{abstract}

J. Draeger $(\bowtie)$

Department of Ophthalmology, Hamburg University,

Leinpfad 96,

22299 Hamburg, Germany

e-mail: draeger-hamburg@t-online.de
Keywords Glaucoma · Intraocular pressure . Hans Goldmann · Roberto Sampaolesi

Richard Banister [1] reported in 1622 the importance of elevated intraocular pressure. The precise measurement was then impossible, and a follow-up during the day was not usual. It is now well known that it took more than 200 years before Albrecht von Graefe [2] developed the first "tonometer" in 1862 (Fig. 1).

However, it required almost another 100 years, before Hans Goldmann in 1955 [3] developed the first precise measuring tonometer, introducing the "applanation principle" (Fig. 2).

It took only a few years before Leydhecker [4] compared 10,000 measurements for their reliability.

From his results, Goldmann derived [5] an interval of 10 years between the first tonometric irregularity and the first neuronal damage, even later functional loss. Goldmann stressed the importance of diurnal variation as the decisive cause for glaucomatous damage. Soon it was understood that regular measurements, allowing a precise observation of the diurnal curve only, could be performed by the patient himself. Neither the ophthalmologist in his office nor even the department are able to guarantee eight measurements a day, as Sampaolesi (1974) [6] has reported in his famous book. The first to give the patient his own tonometer were Zeimer and Wilensky, in 1982 [7]. Unfortunately, their instrument was too complicated, and could be applied only in a seating position, lacking the necessary precision.

In 1986 [8], the next real "automatic" self-tonometer was developed: The primary idea was to detect the rise of intraocular pressure when a person enters a microgravity environment under spaceflight conditions (German Spacelab D1-Mission, German-Russian MIR-Mission, German Spacelab D2-Mission) [9] (Fig. 3). 


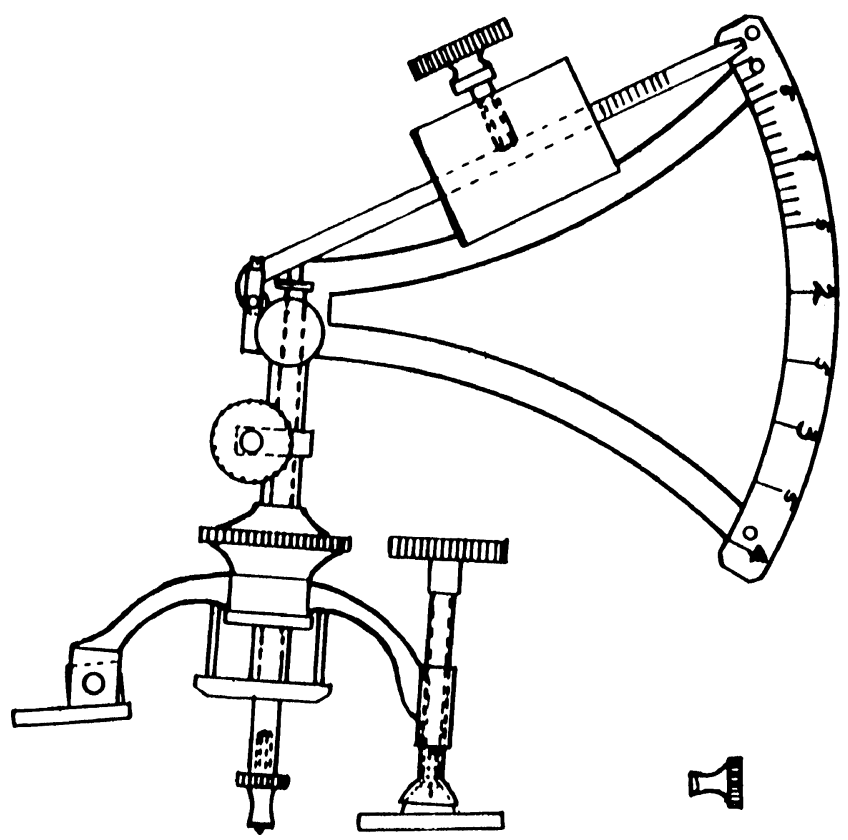

Fig. 1 The first tonometer, developed by Albrecht von Graefe in 1862

Only a few seconds after entering into microgravity conditions, the intraocular pressure rose to more than $100 \%$ of the basic preflight level, which was induced by "fluid shift", movement of fluid along the body upwards.

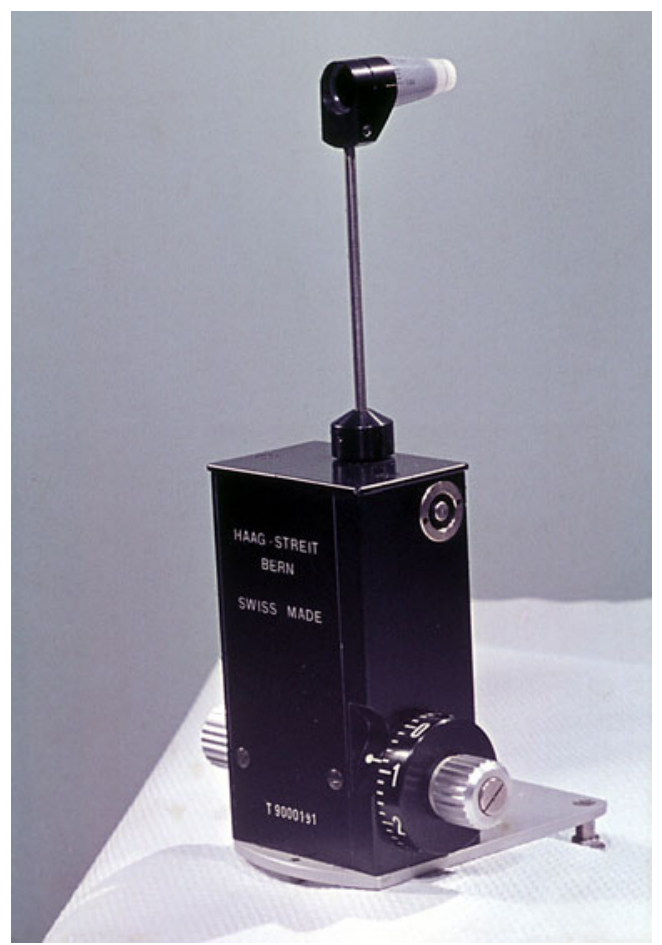

Fig. 2 Applanation tonometer, developed by Goldmann in 1955

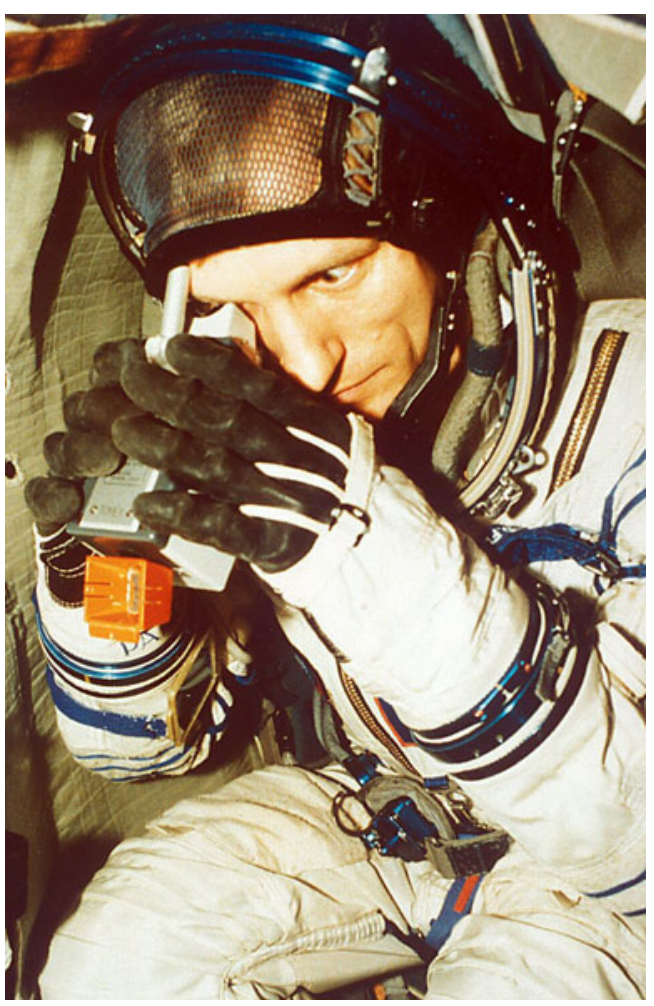

Fig. 3 Tonometry with the automatic self-tonometer during GermanRussian MIR mission

Of course, from the very beginning of this research our idea was to end up with a handsome precise little instrument for the patient to measure himself (Fig. 4).

Advances in microelectronics have led to the development of a fully automatic system, following Goldmann's principle. No longer is the cooperation of the ophthalmologist needed to define the applanation circle of $7.35 \mathrm{~mm}^{2}$. This is controlled by an infrared detecting system. Possible additional reflectivity of the surrounding tear film is defined by " 0 Applanation" at the moment of first contact, measuring the zone of capillary

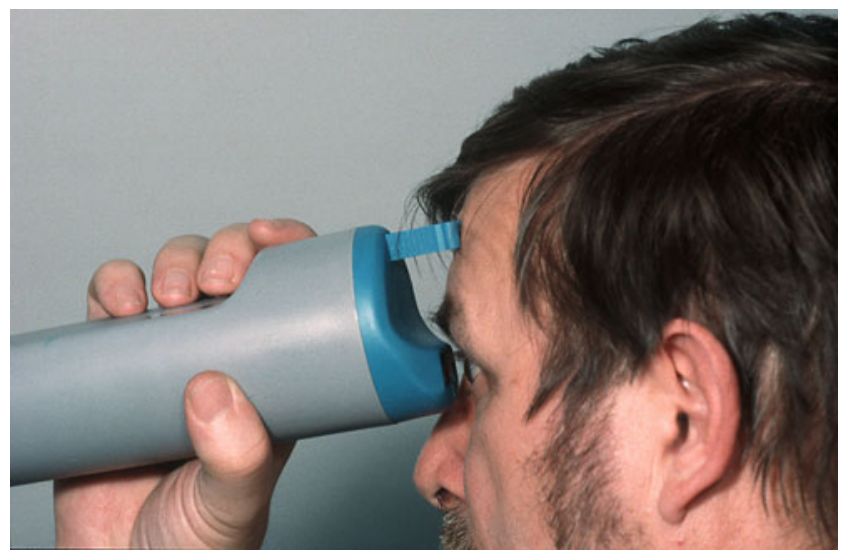

Fig. 4 Application of the new self-tonometer by the patient 


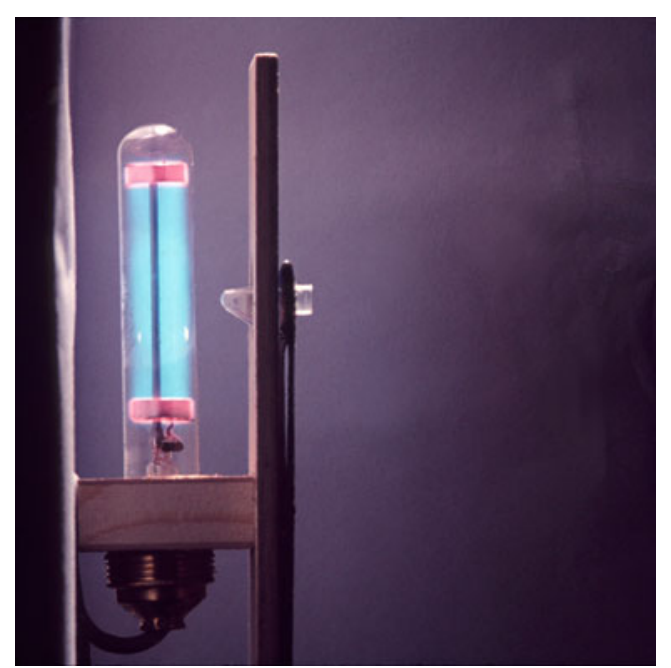

Fig. 5 Automatic ultraviolet disinfection system for the automatic self-tonometer

adhesion, calculating this for defining the final applanated area. A microprocessor regulates the power until reaching an applanation diameter of $3.06 \mathrm{~mm}$. At this moment, the movement is stopped, the necessary force is indicated on the display for the patient, and at the same time this can be transmitted by telematic system to the ophthalmologist.

An important assumption for the practical use by the patient himself is reliable disinfection. For instance, when using a Schiötz tonometer, cleaning and disinfecting the different mechanical parts is very difficult. On the contrary, the smooth surface of the applanation body can easily be cleaned as well as disinfected [10] (Fig. 5).

Technical preconditions are the optimal distance between the UV source and applanation surface, radiation intensity, and time. Specific topicality came up by the danger of infection with retroviruses (HIV). Therefore complete studies concerning this important field were done by the Bernhard-Nocht-Institut, Hamburg [11, 12], where the effectiveness of our system could be proven.
Using this self-tonometer on the one hand the patient himself can register the diurnal curve values (Fig. 6).

Meanwhile, telematic systems allow for the direct transmission of the tonometric values to the doctor's office. G. Michelson [13] at Tübingen was the first who, cooperating with Siemens Company, developed such a telematic system and introduced it into clinical practice. In the United States, Hughes et al. [14] used this system for routine glaucoma follow-up.

Using a similar principle, the Tost group at Greifswald University followed-up a group of 25 glaucoma patients [15]. They not only used a dense diurnal curve of intraocular pressure but also measured and transmitted blood pressure. This allowed for calculating ocular perfusion pressure, which is the most important risk factor in pathogenesis of the glaucomas [16]. Of the participants in the study, 34\% showed a diurnal variation of more than $5 \mathrm{mmHg}$, meeting Goldmann's and Sampaolesi's precondition.

The second study of this group evaluated 3,282 measurements of ocular perfusion pressure. The mean value was found to be between 40 and $50 \mathrm{mmHg}$ - lower values in more than $14 \%$ of the cases. These cases furthermore showed a diurnal variation of $7 \mathrm{mmHg}$ or more. The lowest values for ocular perfusion pressure, 13-14 mmHg lower than the mean values, were found very early in the morning, when there is normally no control process by the ophthalmologist.

The simultaneous combination of these two values thus means a great progress as well for early detection as precise follow-up of the glaucomas.

Many patients at the same time suffer from hypertonus and are treated with strong systemic blood pressure medication, which at the same time reduces ocular perfusion pressure.

In conclusion, we can state that besides Goldmann's and Sampaolesi's advice for dense diurnal tonometric measurement, simultaneous control of blood pressure and circulation of the ocular perfusion pressure might be further progress in the reliable detection and follow-up of our glaucoma patients [17]
Fig. 6 Diurnal curve of otherwise undetected beginning glaucoma

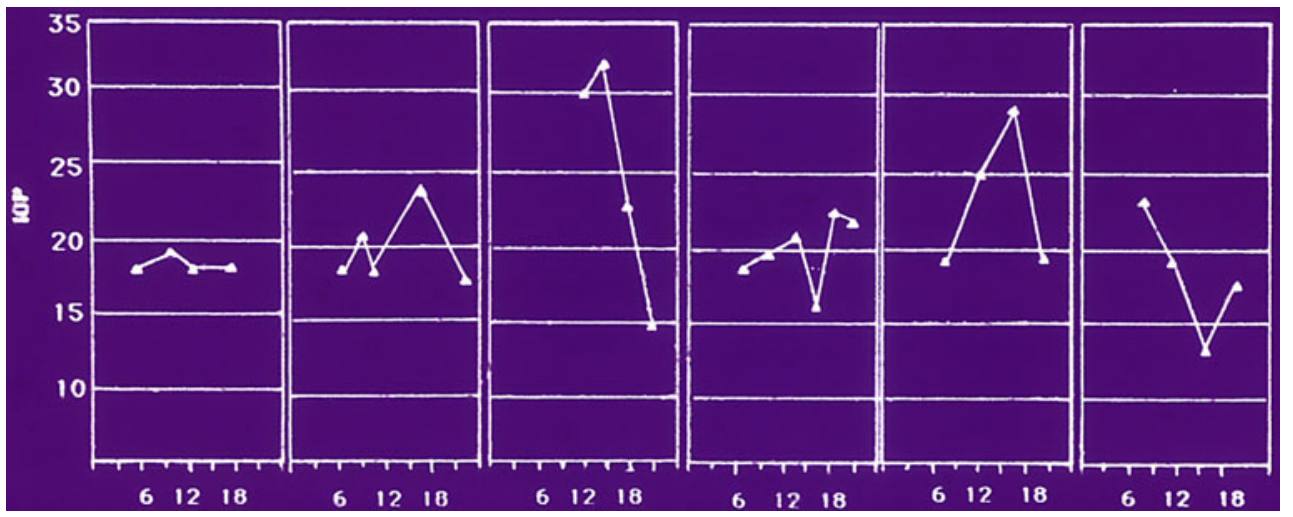




\section{References}

1. Banister R (1622) Breviary of the eyes. In: A treatise of one hundred and thirteen diseases of the eye and the eye-lids. London

2. Graefe Av (1852-1870) Die Briefe Albrecht von Graefes an F.C. Donders

3. Goldmann H (1955) Un nouvea tonomètre à applanation. Bull Soc Franc Ophthalmol 67:474-477

4. Leydhecker W (1959) Zur Verbreitung des Glaukoma simplex in der scheinbar gesunden, augenärztlich nicht behandelten Bevölkerung. Glaucom Ophthal 13:359-388

5. Goldmann H (1958) International Glaucoma Conference, Liège

6. Sampaolesi R (1974) Curva diaria de presión. L. El Glaucoma, 175-190. Editorial Medical Panamericana, Buenos Aires

7. Zeimer RC, Wilensky JT (1982) An instrument for selfmeasurement of intraocular pressure. IEEE Trans Biomed Engng 29:178-183

8. Draeger J (1986) Wirt: Tonometrie in der Schwerelosigkeit. Klin Mbl Augenheilk 188:505-508

9. Draeger J, Groenhoff S, Hock B, Klemm M (1993) Optimierung des automatischen Selbsttonometers durch ein akustisches Kontrollsignal und eine verbesserte Fixieroptik. Ophthalmologe 90:54-57
10. Draeger J (1970) Einfache Möglichkeiten zur Tonometersterilisation. Klin Mbl Augenheilk 157:70-74

11. Schmitz H, Draeger J (1986) Inaktivierung von HTLV-III/LAV durch UV-Bestrahlung und durch chemische Desinfektion. Klin Mbl Augenheilk 189:154-157

12. Schmitz H, Draeger J, Emmerich P (1990) Tonometersterilisation. Inaktivierung von Herpes simplex Virus Typ I (HCV-I) und Adenovirus (Typ 2) durch ultraviolette Bestrahlung. Klin Mbl Augenheiok 196:225-227

13. Draeger J, Michelson G, Rumberger E (2000) Continuous assessment of intraocular pressure - telematic transmission, even under flight- or space mission conditions. Eur J Med Res 5:2-4

14. Hughes E, Spry T, Diamond J (2010) 24-h monitoring of intraocular pressure in glaucoma management: a retrospective review. J Glaucoma 12:232-236

15. Jürgens C, Tost F (2006) Fortschritte in der geriatrischen Betreuung durch Telemedizin. Ophthalmologe 103:749-754

16. Jürgens C, Antal S, Henrizi K, Großjohann R, Tost F (2009) Fluktuation des intraokularen Augendrucks - ein intraindividueller Vergleich zwischen $24 \mathrm{~h}$-Teletonometrie-Monitoring und ambulanter Augendruckmessung. Klin Mbl Augenheilk 226:459-465

17. Draeger J, Rumberger E (2002) Eine technische Lösung zur direkten Messung des intraokularen Perfusionsdrucks. Spektrum der Augenheilk. 16/1:8-10 